\title{
Can meso-governments use metagovernance tools to tackle complex policy problems?
}

\author{
Andrew Connell (1); Steve Martin (1); Emily St Denny (2) \\ 1: Cardiff University, UK \\ 2: University of Stirling, UK \\ ConnellA2@Cardiff.ac.uk \\ martinsj@cardiff.ac.uk \\ emily.stdenny@stir.ac.uk
}

This work was supported by the Economic and Social Research Council under Urgency Grant number ES/N00745X/1.

Accepted Manuscript: This is a PDF of an unedited manuscript that has been accepted for publication.

\begin{abstract}
In recent years, a range of countries have devolved significant powers, responsibilities and funding to the regional level. This paper explores how and why the resulting meso-governments may use the tools of metagovernance. A detailed empirical analysis of homelessness policy in Wales found that skilful deployment of metagovernance tools enabled its meso-government to exploit the advantages of geographical and relational proximity to policy communities, while mitigating some of the constraints of its intermediate constitutional status, including limited formal powers and policy capacity. Junior government officials played multiple roles in homelessness networks, shaping and steering them through active network management while also participating in them. This 'governor-participant' role blurs the distinction made in the existing literature between 'hands-on' and 'hands-off' metagovernance tools. It also shows that, in the case of mesogovernments at least, it is possible for low-ranking officials to exercise greater agency in policy development than has previously been assumed.
\end{abstract}

Key words: metagovernance, meso-government, governance, policy-making, networks, devolution, regionalism, homelessness

Acknowledgements: We are grateful to colleagues at Cardiff and Swansea universities, and to the anonymous reviewers, for their comments and suggestions on previous versions of this article. We would also like to express our special thanks to all those in the Welsh homelessness sector and elsewhere who gave so generously of their time to participate in our original research. 


\section{INTRODUCTION}

Recent years have witnessed a trend towards increasing regionalisation in a range of different countries which has resulted in the growth of meso-level governments and their powers $($ Hooghe and Marks, 2016). At the same time there has been significant scholarly interest in metagovernance as researchers have sought to understand ways in which governments and other actors seek to address complex policy problems ( $\left(\frac{\Phi}{\phi r e n s e n}\right.$ and Torfing, 2009; Torfing, 2016). This paper brings together these two developments through an exploratory study of whether, how and why meso-level governments use the tools and techniques of metagovernance to develop and implement policy agendas.

Our analysis shows that meso-level governments may use metagovernance tools in ways that have not hitherto featured prominently in the metagovernance literature. It offers three main contributions. First, it identifies a range of factors that aid metagovernance practices at the meso-government level. Second, it shows how a meso-government can act as 'governor-participant' in networks, which blurs the distinction in the existing literature between 'hands-on' and 'hands-off' forms of metagovernance. Third, it suggests that in the case of meso-governments, metagovernance may be practised by much more junior officials than previous studies have suggested.

The paper proceeds as follows. The next section examines the concepts of metagovernance and meso-government and specifies our research question. We then outline our research methods. Next we describe the case of homelessness policy in Wales. We then present our findings. The penultimate section discusses our main findings. The final section explores the implications of our study for theories of metagovernance and suggests further research to test the wider applicability of our findings.

\section{MESO-GOVERNMENT AND METAGOVERNANCE}

Meso-level governments sit between the national and local levels and can encompass a very

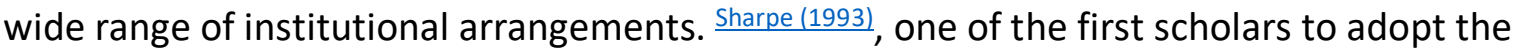
term meso-government, applied it to county councils, the highest tier of local government in the UK. But more recently it has come to be seen as being qualitatively different from both the national and the local. Hooghe et al (2016:15) suggest that a hallmark of mesogovernments is that they 'exert self-rule within distinct homelands', which implies a level of autonomy and a degree of permanence and identity which extends beyond the local and encompasses more than mere administrative functionality.

Metagovernance has been characterised as a reconfiguration of state primacy in response to a putative loss of powers resulting from social, economic and political change ( $\frac{\text { Peters, } 2010}{}$ ). However, in the case of meso-governments, whose formal powers are often already curtailed by material, constitutional and institutional factors connected to their place in a national territorial hierarchy, metagovernance can also be seen as means of building policy capacity to overcome the limitations imposed by their subordinate status.

The concept of metagovernance is grounded in an extensive literature on governance networks theory. Although this has developed from a number of distinct traditions, $\underline{\text { Klijn and }}$ 
Koppenjan (2012) helpfully identify some common assumptions and concepts. They suggest that policy and service delivery are seen as emerging from complex processes of interaction between networks of interdependent actors, whose strategies are framed by their (differing) perceptions of problems and solutions. The complexity created by multiple interactions means that networks require guidance and management, a process described by $\underline{\text { Jessop (2016: } 9)}$ as 'the governance of governance' and by Torfing (2016: 525) as 'metagovernance', which he defines as 'deliberate attempts to facilitate, manage, and direct interactive governance areas without undermining their capacity for self-regulation too much'. Blanco et al (2011) argue that the concept of governance networks has often been depicted as a response to post-modern and post-industrial social and economic changes which have reduced the capacity of the state to direct policy change. The closely related concept of the 'hollowing out' of government developed by $\frac{\text { Rhodes }}{(1997 ;}$ 2007) argues that central government's transfer of responsibility for service delivery to a range of other actors meant that although it was a participant in networks, it no longer exercised direct control of them. However, proponents of the concept of metagovernance suggest that while the range of tools and resources at the state's disposal have changed, and some have been diminished or lost, the state has not become merely one actor among many within governance networks. Networks continue to operate 'in the shadow of hierarchy cast by public and/or private metagovernors... who are capable of regulating and reducing the autonomy of the network' (Sørensen and Torfing, 2009:236). In many cases the state, even at the local level (Fenwick et al, 2012), may use the management of networks as a means to reconfigure its capacity for action and maintain its primacy in policy and implementation.

Dommett and Flinders (2015) propose a demarcation between the 'governance of governance' view of metagovernance, associated with scholars such as Sørensen and Torfing, and a more state-centric relational approach, associated with scholars such as Marsh (2011). However, this

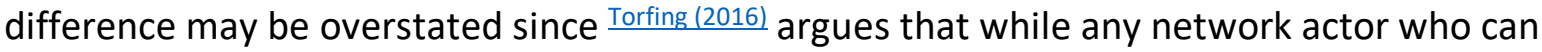
command sufficient policy tools may act as a metagovernor, in practice state actors usually enjoy advantages over other potential metagovernors, because they command, and have the time and experience to deploy, a greater number and range of tools, including funding, staff and the legal coercive powers to underpin their authority.

Sørensen and Torfing (2009) and Torfing (2016) identify four categories of metagovernance, which we have applied to frame the empirical analysis presented in this paper. The first is design. A metagovernor can influence the character, composition, scope and time horizons of the network by shaping its rules, norms and procedures. At the time of network formation this may help maintain an openness about which actors need to be involved by focusing on objectives rather than programmes, and later it can maintain or quicken the pace of the work of the network by setting or negotiating milestones. Second, the metagovernor can steer the goals and framework of a network, establish its legal parameters and basis, and construct the overall discursive storyline which defines problems and possible solutions. Setting network goals in ways that align with those of individual actors can make the network more effective by convincing actors of the necessity for collaboration. Collection and diffusion of 'best practices' through the network can shape actors' understanding of the problem and their selection of means to reach their goals. By funding or supporting selected activities, or by shaping distribution of roles among network members, the metagovernor can foster interdependence between them; and network members may be rewarded for 
participation by being granted access to other policy arenas, or by being recognised as particularly trustworthy and valued.

Sørensen and Torfing describe these first two categories as 'hands-off' tools of metagovernance, because they are more concerned with shaping interaction than participating in it. The other two categories are more actively participative, and so may be described as 'hands-on' tools. Thus the third category relates to a more active role in network management, seeking to support network participants in resolving differences and reducing transaction costs of participation by, for example, providing resources, including resources for meetings and learning opportunities, and by agenda-setting and arbitration to prevent and defuse conflict. Finally, the metagovernor can participate directly in the network, influencing outcomes through active leadership, coalition building and argument. This may also include fostering trust within the network by displaying, unilaterally if necessary, trust in network members. Sørensen and Torfing argue that in practice, a combination of hands-on and hands-off approaches, responding to different imperatives at different stages of the network's operation, is likely to prove most effective. Hands-on metagovernance will, they suggest, be more common in policy areas that relate to core functions of the state, or to those deemed to be strategically important: that is, in areas where failure would have - politically or literally - fatal consequences.

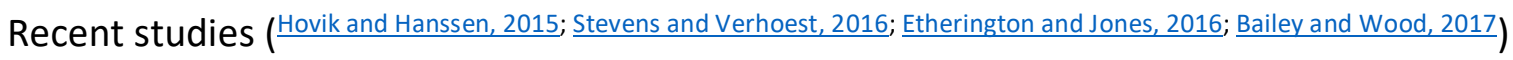
have used Sørensen and Torfing's typology to analyse how national governments use metagovernance tools in their dealings with regional and/or local actors. Our analysis addresses a different focus, namely the exercise of metagovernance by a meso-government, and specifically whether a meso-government can use the tools of metagovernance to tackle complex policy problems, and how and why it might choose to do so.

Our study is exploratory and is underpinned by the observation that while mesogovernments lack of some of the policy levers that are available to national governments, they have access to a range of quasi-national resources (such as legislative powers) and quasi-local relationships (including proximity to local actors and the ability to cultivate a greater breadth and depth of interactions with them). Our hypothesis is that this blend of formal powers and local connectivity means that skilful deployment of the tools of metagovernance may enable policy actors at meso-level to exploit the advantages, and offset some of the limitations, of their intermediate position between national and local government. If it is the case that metagovernance is an important part of a mesogovernment's policy repertoire, studying it in this context may add new insights to the existing literature, which has hitherto focused largely on metagovernance at national and local levels.

\section{DATA AND METHODS}

Our empirical analysis focuses on the development and implementation of one of the most significant pieces of primary legislation enacted to date by the devolved National Assembly for Wales, the statutory framework for homelessness services contained in Part 2 of the Housing (Wales) Act 2014. 
We selected this case following a series of exploratory interviews and a roundtable discussion during which we asked well placed informants to identify exemplars which demonstrated how the devolved institutions in Wales develop and implement policy. Focusing on this case for in-depth analysis enabled us to understand in some detail the process and factors that were in play in a particular policy episode at the meso-level. Clearly, we have to be cautious about generalising from a single case. However, the many Welsh policy practitioners, as well as academics, with whom we consulted in the course of the research suggested that this case offers a recent and relatively ambitious example which shows how the Welsh Government can deploy the powers and policy available to it to best effect. Adapting Goertz's Avoid Overdetermination Rule ( $(\underline{\text { Goertz, } 2016})$, we believe that in order to understand a phenomenon - in this case, meta-governance - it can be most fruitful to study an example which approaches more closely to an 'ideal type' of that phenomenon. The understanding gained from this study can then be tested in other settings and combined with insights gained from them.

We collected primary data from four sources. First, as noted above, in order to identify potential cases and the key issues to be investigated, we conducted a series of semistructured interviews and a three-hour focus roundtable discussion with senior civil servants from the Welsh and UK government, senior local authority officers and leading academics. The roundtable discussion was recorded and the key findings written up in a report that was circulated to participants for checking. In order to allow an honest and open discussion, it was conducted under the 'Chatham House Rule' which stipulates that information disclosed in a meeting may be used freely on condition that the identity of the speaker, and of all other participants in the meeting, is not revealed ( $\underline{\text { Chatham House, nd }}$ ).

Second, having identified our case, we analysed in detail consultation papers, reports, and research on homelessness produced and commissioned by the Welsh Government and other stakeholders in Wales since 1999, and official reports of debates in the National Assembly during the passage of the legislation in 2013-14, to identify the main episodes and actors in the development of the policy.

Third, we conducted in-depth, semi-structured interviews with 16 Welsh Government officials, academics, politicians, and local government and third sector actors who had played significant roles in development and implementation of the homelessness legislation. Interviews were conducted in summer 2016 on a non-attributable basis in settings of interviewees' own choosing. Most interviews were conducted face-to-face but, at the interviewees' request, two were undertaken by telephone. They typically lasted about an hour and were recorded, professionally transcribed, and made available to interviewees for factual correction or clarification (although only a very few minor corrections were requested). Transcripts were then coded using a manual thematic analysis to identify principal themes.

Our initial selection of interviewees focused on individuals who were identified as key actors from our analysis of documents and knowledge of this sector and we managed to interview all of the key actors with the exception of the minister who had overseen the passage of the legislation. However, several of the interviewees had worked closely with him, including in some cases as trusted specialist advisers, and they were able to offer us insights into his 
thinking and actions. Our initial sample was shown to have included almost all of the other important actors, but we adopted a 'snowball' sampling method, asking interviewees to identify others who had been involved ( $\underline{\text { Devine, } 1995}$ ) and this yielded one additional informant who provided particularly valuable information about implementation of the policy.

Although, as we shall show, there was a substantial and broad consensus among interviewees, there were points of significant disagreements and we are confident that our selection captured this diversity of positions.

The roles of the interviewees quoted verbatim in this paper are shown in Table 1.

Table 1:

Interviewees cited

\begin{tabular}{|l|l|}
\hline Interviewee & Date interviewed \\
\hline Academic informant 1 & 6 July 2016 \\
\hline Academic informant 2 & 19 July 2016 \\
\hline Consultant & 10 June 2016 \\
\hline Former Assembly Member & 23 August 2016 \\
\hline Local Government informant 1 & 5 August 2016 \\
\hline Third Sector informant 1 & 25 July 2016 \\
\hline Third Sector informant 2 & 25 July 2016 \\
\hline Welsh Government informant 1 & 1 August 2016 \\
\hline Welsh Government informant 2 & 14 September 2016 \\
\hline
\end{tabular}

Our fourth data source was a three-hour policy reunion which brought together seven of our key informants and an academic discussant to discuss the key emerging findings from our documentary analysis and interviews. Policy reunions or witness seminars - the terms are effectively synonymous, although in using the term policy reunion we follow the

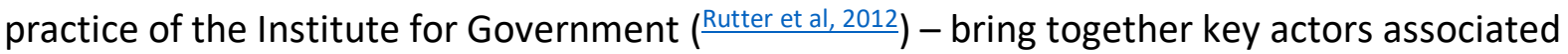
with a particular historical or policy episode to reflect on their experiences and deliberate, in a structured way, on key issues, critical incidents and areas of agreement and differences

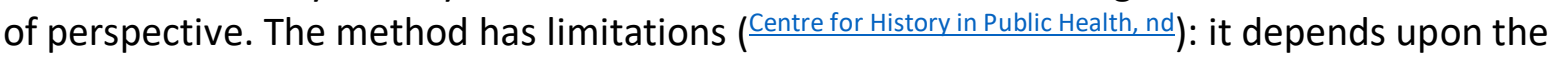
ability to select and gather suitable participants, and in addition to the questions of candour and reliability of recall which are shared by other approaches which rely on oral testimony, the structured group setting may sometimes inhibit frank discussion. But it can produce data which, when examined alongside other evidence, help to provide additional insight into issues such as the motivation, underpinning assumptions, and dynamics of groups and individual actors. In our case it also provided an opportunity to test and affirm or revise key findings.

Participants in the policy reunion are shown in Table 2. 
Table 2:

Policy reunion participants

Welsh Government witness

Third Sector witness

Local Government witness 1

Local Government witness 2

Academic witness

Ministerial Adviser witness

Local Government witness 3

Academic discussant: Professor Alex Marsh

Chair: Professor Steve Martin

All of the participants in the policy reunion were still active in the sector: consequently, they requested that, as in the earlier roundtable, the discussion be conducted under the 'Chatham House Rule'. This is a departure from the usual (but not invariable) practice of policy reunions/witness seminars ( $($ History of Modern Biomedicine Research Group, nd $)$ but was necessary to ensure open and honest discussion. The reunion was audio recorded and the recorded data were coded using a manual thematic analysis to identify principal themes within them. A draft report was then compiled and made available to interviewees for factual correction or clarification (again, only a few minor corrections were requested) before a final version of the report was published.

\section{DEVOLUTION AND HOMELESSNESS POLICY IN WALES}

Until 1999, most areas of domestic policy in Wales were the responsibility of the Welsh Office, a department of the UK Government, and operated within legislative frameworks set by the Westminster Parliament. Since 1999, successive Acts of the UK Parliament have first created devolved institutions (Government of Wales Act 1998) and then extended their powers (Government of Wales Act 2006, Wales Acts 2014 and 2017). An executive, responsible to the Assembly and now known as the Welsh Government, was established in 2001 and recognised in law in 2006 (s45, Government of Wales Act 2006). In 2011 the Assembly was granted full primary legislative powers in devolved matters under part 4 of the Government of Wales Act 2006. The Wales Act 2017 gave the National Assembly full legislative powers in all matters not explicitly reserved to Westminster, including health, education, housing, local government, agriculture, the environment and significant areas of transport and economic development. It also devolved limited taxation and borrowing powers to Wales. Approximately 80 per cent of the Welsh Government's overall expenditure budget continues to come from a block grant from the UK Treasury the overall size of which is determined by UK government's decisions about levels of spending on public services in England ( $\frac{\text { Welsh Government, 2018}}{}$ ). However, the Welsh Government determines how it distributes this funding between devolved services. 
The Welsh Government therefore possesses the characteristics of a meso-government as

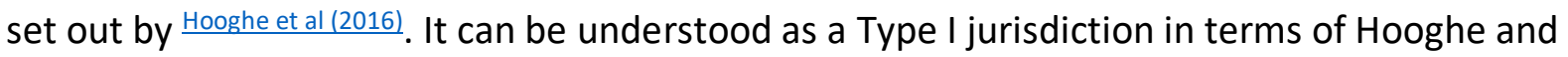
Marks' (2003) classification of sub-national governments because it is responsible for a range of functions and policy areas, its boundaries do not intersect with any other at its level, it is intended to be stable over time, and it possesses representative institutions. In

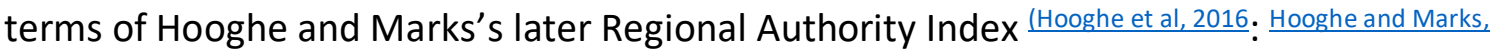
$\underline{2016})$, it exercises a significant degree of self-rule ${ }^{1}$ and has 'the capacity to make legitimate

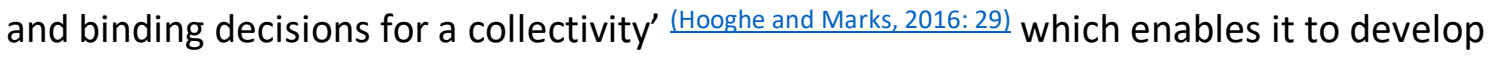
distinctive policies.

As explained above, this paper focuses on the development and implementation of legislation to tackle homelessness from 2009, when the Welsh Government publicly identified the need to reform the existing statutory framework (Welsh Assembly Government, 2009), until 2015, when Part 2 of the 2014 Act came into force. This reform of homelessness policy entailed substantial, innovative, distinctive and apparently successful changes to an existing statutory framework which Wales had shared with England. Since 1978, local authorities in Wales (and England) have had a statutory duty to secure long-term housing for homeless persons who met certain eligibility criteria. After 1999, homelessness was 'always...on the radar' (Academic informant 1) of Welsh policy makers who produced their own national homelessness strategies and used their secondary legislative powers to make marginal changes to the inherited statutory framework. What is important during this period, however, is that that framework came to be seen as inadequate by many homelessness policy actors, within and beyond government.

There were three reasons for this ( $(\underline{\text { Clapham et al, 2009; }}$ Mackie, 2015): the existing framework offered little help to homeless people who did not meet all its eligibility criteria, rising numbers of households in Wales were being placed by councils in (often costly and unsatisfactory) temporary accommodation while their applications were being processed, and there was an increasing focus on the importance of preventing homelessness. Prevention acquired growing prominence in successive Welsh National Homelessness Strategies and several local authorities developed their own non-statutory preventative approaches, sometimes with support from the Welsh Government (onnell et al, 2017). Ultimately, Part 2 of the Housing (Wales) Act 2014 would give councils additional and substantial duties to help people who are threatened with homelessness to retain their accommodation, and to help people who are actually homeless to secure interim accommodation. These obligations are owed to almost all people in need of help, and not just those who meet the restrictive eligibility criteria for the long-term housing duty. These reforms are widely seen as a success. They achieved many of their key aims and have heavily influenced subsequent legislation in England (Fitzpatrick et al, 2017; Mackie et al, 2017).

Homelessness had a particular political significance in Wales. Wanna (2014:566) notes that subnational political leaders 'frequently juxtapose their political objectives or leadership styles in contrast to central or national leaders/governments', and Welsh Ministers were keen to establish a socially progressive policy agenda, that was clearly differentiated from

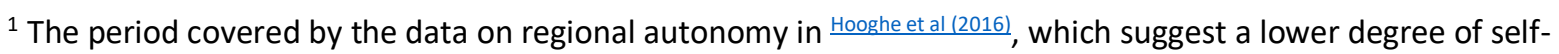
rule for Wales, ends at 2010 - that is, before the National Assembly gained full primary legislative powers and before fiscal powers started to be devolved to Wales.
} 


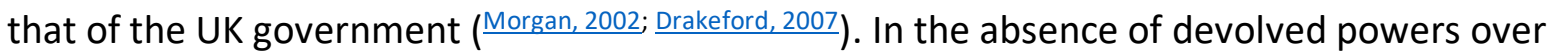
social security or (until very recently) taxation, homelessness became an 'emblematic' issue (Academic informant 2) in which Wales could develop a distinctive approach. Thus, when it became likely that primary legislative powers would be devolved, Welsh policymakers were keen to identify policy areas in which they could demonstrate that the new legislative powers would make a difference. Homelessness, which was heavily embedded in legislation and was already the subject of considerable networked governance by the Welsh Government, quickly emerged as a leading contender (Third Sector Witness, Policy Reunion).

\section{FINDINGS}

The data gathered from our initial roundtable, the documentary analysis, interviews and policy reunion all pointed to the existence of a pattern of consistent and deliberate network management by the Welsh Government, which reflected all four of the categories of tools of metagovernance identified by Sørensen and Torfing and we therefore use their typology to structure the presentation of our key findings.

\section{Network design}

Welsh policy makers operate in a small country which has a small number of governing institutions and often close-knit policy communities. This makes it possible to bring together the main actors from the private, public and third sectors, at least in a physical and literal sense $\left(\frac{\text { Rabey, } 2015}{}\right)$. As a result, members of Welsh sectoral policy networks know each other well and interact frequently. Furthermore, the limited policy capacity of the small civil service in Wales prompts policymakers to rely more on non-governmental actors for information and support. (Both these factors have also been identified as characteristic of the so-called 'Scottish policy style' (Cairney et al, 2016:340).)

Consistent with this approach, our data showed that the Welsh Government played an important role in establishing and designing institutional networks relating to homelessness. Although the pre-1999 Welsh Office had of necessity cultivated relationships with selected partners (Deacon, 2002), devolution produced a development of this practice whereby close engagement with a range of actors became the norm:

I think it was more difficult with the Welsh Office quite frankly. It was a much more up and down kind of relationship and became much more of a critical friend partnership with the Assembly. (Third Sector informant 1)

The Welsh Government fostered a set of compact, well-integrated, and more or less formal networks which enabled a flow and exchange of information between it and key actors from local government and the third sector. Two networks were particularly important in the case of homelessness policy. The Local Authority Homelessness Network, which was 'very much a part of the development of [the legislation]' (Local Government informant, 1), is discussed later, in the fifth section. The Homelessness Strategy Working Group (HSWG) was originally convened in the early 2000s to monitor and inform the development of the first devolved National Homelessness Strategy (Third Sector informant 1; former Assembly 
Member; Welsh Government informant 1) and included local authority and third sector stakeholders. It continued to exist beyond its original purpose because its members saw that it had value as a forum for

two-way information and debate around the development of national policy [and a]...sounding board and a way of keeping channels very much open with the various sectors. (Welsh Government informant 1)

[it] was a group which may have been a talking shop...but which formed the basis for something productive that's now come to fruition. (Consultant)

Two features of the HSWG are particularly noteworthy. First, while all interviewees depicted it very positively, it continued to be 'owned' by the Welsh Government in the sense that it was convened and chaired by civil servants who emphasised that its role was advisory with responsibility for policy decisions remaining with Ministers (Welsh Government informant 1). Second, it existed to debate and inform strategies and policy frameworks (and, thus, objectives), rather specific programmes. This enabled it, as Sørensen and Torfing's analysis would suggest, to take fairly open and pragmatic decisions about its membership:

Mostly [peak organisations] but we do have some individual representatives from the third sector and from Local Government as well...I think we started off with the representatives and then we invited on people as the group felt would be helpful. (Welsh Government informant 1)

\section{Steering network goals and framework}

In addition to establishing and designing homelessness policy networks, the Welsh Government took an active role in steering their operation and supporting the work of networks which were not of its own creation. Ansell et al (2017) have identified the value of collaborative policymaking in creating shared problem definitions, and developing and implementing solutions, and our case presents two examples of this. The Local Authority Homelessness Network brought together homelessness service managers from the 22 local authorities (Local Authority informant 1). It was managed by the Welsh Local Government Association (WLGA), but funded by the Welsh Government to conduct

pieces of work...on behalf of Welsh Government or on behalf of the Local Authorities or a sort of mixture of the two, looking at...good practice and developing...practice and looking at implementation. (Local Authority informant 1)

This network brought into policy development and implementation practitioners whose views were seen as being often:

much more pragmatic and largely constructive about things [than the official positions of the WLGA, which represented the local government sector as a whole]. (Consultant) 
[The Homelessness Network is] working with officials, Local Authority employees, and sometimes WLGA is a members' [= local politicians'] response and sometimes there is a slight difference. (Local Authority informant 1 )

The second example concerns the creation of a shared policy narrative. In 2011, with the granting of full primary legislative powers, the Welsh Government commissioned a team of academics and consultants, well known and respected in Welsh housing circles, to examine, and explore stakeholder perspectives on, the existing statutory framework and to identify options for improvement. Known as the 'Mackie Review'2 (Fitzpatrick et al, 2017), this was credited by our informants with creating a remarkable consensus about the nature and causes of homelessness in Wales.

The review team adopted a highly participative approach, engaging widely with local authorities, housing providers and other stakeholders across Wales:

Everyone who had an interest had an opportunity to get involved. Lots of work around Wales, road-shows. (Welsh Government informant 1)

There was definitely more of the being out and about and actually speaking to the grassroots. (Academic informant 2)

Although it drew significantly on comparative data about approaches outside England and Wales, and administrative data from local authorities about their responses to applications for homelessness assistance, a very important part of the review was the series of workshops with local authority practitioners and other stakeholders, from which the review team developed a substantial evidence base ( $\left(\frac{\text { connell et al, } 2017}{}\right)$. Invitations were distributed widely: the team identified some invitees, particularly through networks like the Local Authority Homelessness Network, and then asked them to pass invitations on to anyone they thought might want to attend. Discussions were designed to elicit participants' views as openly as possible:

This is an open discussion. It's your view. You don't have to conform to the views of your management. We just want to know about your perspectives collectively ... (Academic informant 1 )

They succeeded in doing so, and because the Review's recommendations were substantially informed by evidence about the best existing local practice, practitioners had some sense of ownership of them and a common storyline was developed:

there was a point at which people got behind it and that came halfway through the review, because at the start there were a lot of conflicting ideas...about which direction [the review] might go...The process [the review] ... carried people with [it]. It was a process, not just an output. (Academic witness, Policy Reunion)

\footnotetext{
${ }^{2}$ Named after its principal investigator, Dr Peter Mackie of Cardiff University.
} 
Later, the Local Authority Homelessness Network organised a programme of implementation training to help local authority and third sector homelessness practitioners move to the new ways of working which the reformed framework required. Crucially, the programme, which because of the small size of Wales was able to 'train everybody, every case worker across the country' (Local Authority informant 1), was designed and delivered by a joint team from the Network, the Welsh Government homelessness policy team, and a significant third sector housing advice organisation. This, and the fact that local authority and third sector staff were trained together, meant that it contributed significantly to developing and disseminating a shared view of the nature and purpose of the reforms (Local Authority informant 1).

These are clear examples of the use of 'hands-off' tools of metagovernance, although they were exercised in a way that entailed a fairly closely engaged role for Welsh Government officials because of the small size of Wales and of its homelessness policy community.

\section{Active network management}

Turning to 'hands-on' tools, interviewees cited numerous examples of active network management by the Welsh Government, including the implementation training described above. By the late 2000 s there was broad agreement within the Welsh homelessness policy community about the shortcomings of the existing statutory homelessness framework and the principles which should underpin reforms. But there were significant disagreements between the local authorities, speaking through their representative body, the WLGA, and some other network members, on matters such as the likely resource costs of reforms (Consultant; Third Sector informant 2). Welsh Government officials and ministers played an active and vital role as arbitrators in intra-network conflicts and were able to make decisions which were accepted as binding by all parties.

These decisions were conditioned by an awareness that while the Welsh Government had ultimate legislative and financial responsibility for the homelessness framework, it was local authorities that would implement it. Nonetheless, the open lines of communication which existed through formal networks facilitated the making, and subsequent acceptance, of these decisions (Third Sector informant 2; Consultant). Welsh Government Ministers also played a role in network management by signalling their strong support for collaboration between actors.

\section{Active network participation}

Active participation by Welsh Government officials was a distinctive feature of formal and informal networks:

I've had the opportunity to go to England a few times and present and I would say that's one of the big things that struck me [about Wales], the involvement and the real consideration of what other agencies think about the legislation and their opinions...It has been a very, very collaborative piece of work and I think that's one of its strengths really. (Local Authority informant 1 ) 
In particular, interviewees presented the leader of the Welsh Government's Homelessness Policy team as having been consistently engaged with and accessible to other actors: I would give [that official] and his 'team' - two or however many it is, it's a very small and delicate team, I would give them lots of credence really in terms of being open to...coproduction (Consultant)

On some occasions this engagement took the form of building coalitions within networks to circumvent opposition. For example, when there were disagreements with the WLGA over resource costs a decision was taken to seek alternative perspectives from homelessness service lead officers in local authorities to test the claims being made by the WLGA. This was a 'highly tactical' manoeuvre 'to get a more sensible and balanced position from the people who were actually...it was actually respecting their expertise and professionalism' (Consultant).

Another example of active participation in networks by the Welsh Government was the revision of the statutory Code of Guidance for local authorities on provision of homelessness services. Although a code had existed under the previous homelessness legislation, the new statutory framework made it imperative to revise it, and a crosssectoral working group with strong local government and third sector participation was established by the Welsh Government. What is important is that the Group's first Chair was a specialist adviser to the Minister for Housing and Regeneration who was widely respected within the Welsh homelessness sector. Her leadership at an early stage was an important factor in imbuing the group with a sense of 'shared endeavour' (Consultant), which made it a very effective forum for identifying and reviewing problems and possible solutions.

\section{DISCUSSION}

The case of the Housing (Wales) Act 2014 demonstrates that the Welsh Government used metagovernance to develop an innovative policy framework that differed from previous approaches to homelessness in Wales and those adopted across the border in England. The answer to the first part of our research question is, then that a meso-government can use the tools of metagovernance to address a complex policy problem.

Turning to the questions of how and why they might choose to do so, our case shows that, as we anticipated, metagovernance offered the Welsh Government a way of mitigating some of the limitations of its constitutionally intermediate position and maximising the benefits of its geographically and hierarchically intermediate position. In a small country with a tight-knit policy community, it was possible for government officials to establish networked relationships that were comprehensive and extended to the front line of policy delivery. The gap between policymakers and implementers, already small in a country with only a single layer (and a comparatively small number) of principal local authorities below the subnational government, thus became narrower still, and while policymaking and implementation were not fused, they did come much closer to being part of a wider collaborative process. The proximity of the Welsh Government to other actors in the field meant that its practice of metagovernance extended upwards and downwards, involving both ministers and, routinely, relatively junior officials. 
This is a significant finding because one of the principal arguments deployed by advocates of decentralising powers previously held by national governments is that meso-governments are more likely to pursue policies that address the particular needs and priorities of their territories ( $\frac{\text { Kay, 2003; Bradbury, 2003 }}{2}$, while one of the enduring concerns about devolution has been whether meso-government can marshal the capacity and capabilities needed to do this ( Andrews and Martin, 2010).

Our analysis also highlights the importance of combining formal and informal powers and resources. Significant reform of Welsh homelessness policy would not have been achieved without the Welsh Government's law-making powers, personnel and financial resources. The Welsh Government's funding for the 'Mackie Review' and implementation training was vital. Its homelessness and housing policy teams, though small, constituted a core capacity for policymaking, coordination and communication. What is most important is that because homelessness provision in the UK is deeply embedded in a framework of statutory services and duties, significant reform required the ability to make new legislation. The devolution of primary legislative powers to Wales in 2011 was recognised as a step-change in Welsh homelessness reform by the Welsh Government and others.

While these formal powers and resources were necessary, however, they were not sufficient to achieve it effectively. This was partly because statutory homelessness services are delivered by local authorities (and to some extent the third sector), but also because the whole process of policy development, including conceptualisation and definition of problems, identification of policy options, and introduction and implementation of the new framework, required the collaboration of other key actors in the homelessness policy community. By bringing to the table, through managed networks, a wide range of stakeholders, the Welsh Government could achieve decisions that were informed by their experience and understanding of the policy issues and could secure from them a degree of commitment to the reforms, as well as procedural legitimacy.

Metagovernance tools were important not just in the period in which this new policy for tackling homelessness was being actively developed and implemented, but also in the previous decade when the Welsh Government lacked law-making powers and fostered, managed, and participated in homelessness policy networks because there was little else that it could do. However, as its formal powers increased, so did its capability to act as a metagovernor. The prospect of devolution of primary legislative powers, and thus of a 'homegrown' statutory framework, prompted non-government actors to review their approach to collaboration with local and Welsh Government, and to conclude that collaboration offered them the best chance not only of achieving goals which they supported, but of influencing difficult choices that could affect their role. Furthermore, shifting the focus of policymaking from strategies and coordination to taking decisions about legal obligations in what was, as we have seen, a highly politically salient area moved the practice of metagovernance, at times, to a higher level of authority, as Welsh Government ministers became more involved in arbitration and decision-making. Thus, the more formal authority the Welsh Government acquired, the deeper and longer the shadow of hierarchy over metagovernance became.

\section{CONCLUSIONS}


Our analysis demonstrates the usefulness of the theoretical framework developed by $\underline{\text { S } \phi r e n s e n}$ and Torfing (2009) and $\underline{\text { Torfing (2016) }}$ but also offers insights that can develop and build on it, thus extending our understanding of metagovernance.

We found evidence that the meso-government in our case employed all four of the categories of metagovernance described by Sørensen and Torfing. Interestingly though, in practice the boundaries between them were often blurred and practices were deployed concurrently. For example, the implementation training described above is an example of steering the goals and framework of the network by creating a common storyline about the reforms. But it can also be seen as an example of active network management by providing opportunities and resources for the network to function, and, perhaps, as active network participation, strengthening the coalition by demonstrating and fostering trust between Welsh Government, local government and third sector actors.

This blurring of the categories of metagovernance was particularly evident when it came to 'hands-on' and 'hands-off' tools. Welsh Government officials played multiple roles, consistently shaping and steering networks through active network management while also participating in them. These actors can be described as 'governor-participants' who combined the 'hands-off' tools of network design and steering with 'hands-on' tools such as active participation and network management. They were an important means by which the Welsh Government governed networks, and the formal governing resources such as political and legislative authority which the government alone possessed gave these officials a decisive advantage as participants. If, as we have suggested, a characteristic of a meso-level government is a combination of quasi-national formal powers with proximity to wider policy communities and a relatively narrow distance between policymaking and implementation, the governor-participant role can be seen as one which may be particularly important in the case of meso-governments, and its identification offers a new contribution to our understanding of metagovernance.

The final contribution of our study is to highlight the agency exercised by relatively junior officials. $\frac{\text { Sørensen and Torfing (2009) }}{\text { suggest that the strategic and collaborative competences }}$ required for the practice of metagovernance may not be found among lower-level officials. However, our research shows that much of the Welsh Government's day-to-day governance of, and participation in, homelessness policy networks fell to junior, though experienced and well respected, officials in its small homelessness policy team. This may be a particular feature of the exercise of metagovernance by meso-governments which lack the policy capacity possessed by national governments but whose officials are 'closer' to delivery. In our case it was linked to two main factors. First, the relatively small size of the Welsh homelessness sector and the Welsh Government's homelessness team allowed, and probably required, junior officials to take an active metagovernance role as network governor-participants. Second, the salience of homelessness as a policy issue empowered them to take action in the knowledge that they had the backing of their minister. Sørensen and Torfing suggest that hands-on metagovernance is associated with policy areas that are core activities of the state, or which are seen as strategically important. As explained above, in Wales, homelessness was, if not a core function of the state, a highly state-centric policy area and emblematic of the desire to develop a distinctive social policy agenda. 
We acknowledge the limitations of our study based as it is on a single case. Informants highlighted it as an example of successful policy development and implementation for a number of reasons. Homelessness policy sat squarely within the remit of the Welsh Government and had few, if any, direct consequences outside Wales. The statutory framework placed the state in a strong position to bring about change, and there was broad agreement within the small and well-defined Welsh homelessness policy community about the shortcomings of the existing statutory framework. The metagovernance of homelessness policy was, therefore, arguably one of the less complex policy issues facing the Welsh Government. There are other instances where devolved administrations (in Wales and elsewhere) have struggled to secure distinctive policy responses and future research might usefully focus on the exercise of meso-level metagovernance in some of these more complex and contested policy arenas.

Nonetheless, our research demonstrates that, in at least some contexts, the combination of quasi-national powers and quasi-local positioning make metagovernance an important and effective tool for meso-governments. Where its formal resources are limited and/or contested, success in policy development and implementation becomes less a matter of what a government can (constitutionally) do, than of how it does it. At the same time, the ability to make authoritative decisions about law or funding within their territories, in a way that is quantitatively and probably qualitatively different from that of local governments, gives meso-level governments a set of 'hard' powers which incentivises other actors to cooperate. 'Soft steering' metagovernance resources such as provision of funding,

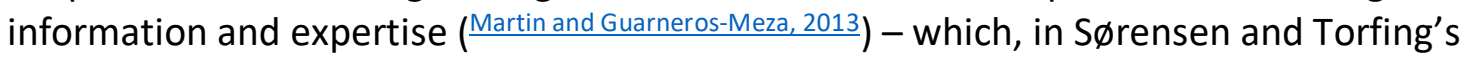
typology may combine network steering and active network management - can be very valuable. In our case study, the Welsh Government's funding and steering the Local Authority Homelessness Network is a notable example of this. However, fundamental policy change may require legislative or funding resources which, within the territory, only the meso-level government possesses.

Further research could usefully investigate whether the findings from research apply in other contexts. It might be valuable to compare the exercise of metagovernance by meso-

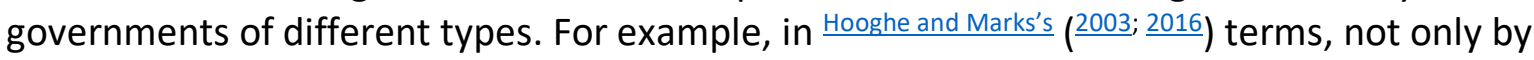
Type I administrations, such as the Welsh and Scottish Governments, but also Type II (taskspecific, non-exclusive, flexible) jurisdictions, and by meso-governments with differing degrees of authority. It would also be useful to explore whether government officials in other contexts take on the role of 'governor-participants' and to investigate whether, as in

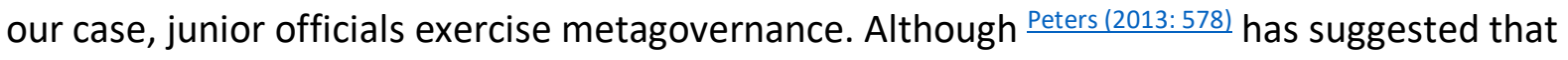
low-ranking officials 'in the field' may be more successful at coordinating implementation networks than senior officials 'in the national capital', in our case it was less senior policy officials who acted as 'governor-participants' in policy networks. This suggests the possibility that the closer, in terms of both geography and hierarchy, a government is to network actors (as it may be at the meso-level), and the more active its metagovernance style, the less of a distinction there is between policy and implementation, and the more opportunities and requirements there are for officials at different levels to act as metagovernors. 


\section{REFERENCES}

Andrews, R. and Martin, S.J. (Year: 2010) Regional variations in public service outcomes: the impact of policy divergence in England, Scotland and Wales, Regional Studies, 44(8): 91934. doi: 10.1080/00343400903401592

Ansell, C., Sørensen, E. and Torfing, J. (Year: 2017) Improving policy implementation through collaborative policymaking, Policy \& Politics, 45(3): 467-86.

Bailey, D. and Wood, M. (Year: 2017) The metagovernance of English devolution, Local Government Studies, doi: 10.1080/03003930.2017.1359165

Blanco, I., Lowndes, V. and Pratchett, L. (Year: 2011) Policy networks and governance networks: towards greater conceptual clarity, Political Studies Review, 9: 297-308. doi: 10.1111/j.1478-9302.2011.00239.x

Bradbury, J. (Year: 2003) The political dynamics of sub-state regionalisation: a neofunctionalist perspective and the case of decentralisation in the UK, British Journal of Politics and International Relations, 5: 543-75. doi: 10.1111/1467-856X.00119

Cairney, P., Russell, S. and St Denny, E. (Year: 2016) The 'Scottish approach' to policy and policymaking: what issues are territorial and what are universal?, Policy \& Politics, 44(3): 333-50.

Centre for History in Public Health (Year: nd) Witness seminars, https://history.Ishtm.ac.uk/witness-seminars/

Chatham House (Year: nd) Chatham house rule, www.chathamhouse.org/chatham-house$\underline{\text { rule }}$

Clapham, D., Mackie, P. and Pritchard, J. (Year: 2009) Homelessness policy in Wales: which path will it take?, In S. Fitzpatrick, D.Quilgars and N.Pleace (eds) Homelessness in the UK: Problems and solutions, Coventry: Chartered Institute of Housing, pp 125-40.

Connell, A., Martin, S. and St Denny, E. (Year: 2017) How can subnational governments deliver their policy objectives in the age of austerity? Reshaping homelessness policy in Wales, The Political Quarterly, 88(3): 443-51. doi: 10.1111/1467-923X.12376

Deacon, R. (Year: 2002) The governance of Wales: The welsh office and the policy process 1964-1999, Cardiff: Welsh Academic Press.

Devine, F. (Year: 1995) Qualitative analysis, In D.Marsh and G.Stoker (eds), Theory and methods in political science (1st edn.), Basingstoke: Macmillan, pp 137-53. 
Dommett, K. and Flinders, M. (Year: 2015) The centre strikes back: metagovernance, delegation, and the core executive in the United Kingdom, 2010-14, Public Administration, 93(1): 1-16. doi: 10.1111/padm.12121

Drakeford, M. (Year: 2007) Social justice in a devolved Wales, Benefits, 15(2): 171-8.

Etherington, D. and Jones, M. (Year: 2016) The city-region chimera: the political economy of metagovernance failure in Britain, Cambridge Journal of Regions, Economy and Society, 9: 371-89. doi: 10.1093/cjres/rsw007

Fenwick, J., Miller, K. J. and McTavish, D. (Year: 2012) Co-governance or meta-bureaucracy? Perspectives of local governance 'partnership' in England and Scotland, Policy \& Politics, 40(3): 405-22.

Fitzpatrick, S., Pawson, H., Bramley, G., Wilcox, S., Watts, B. and Wood, J. (Year: 2017) The homelessness monitor: Wales 2017, London:Crisis UK.

Goertz, G. (Year: 2016) Multimethod research, Security Studies, 25(1): 3-24. doi: 10.1080/09636412.2016.1134016

History of Modern Biomedicine Research Group (Year: nd) Wellcome witnesses to twentieth century medicine, www.histmodbiomed.org/article/wellcome-witnesses-twentieth-centurymedicine.html

Hooghe, L. and Marks, G. (Year: 2003) Unravelling the central state, but how? Types of multi-level governance, American Political Science Review, 97(2): 233-43.

Hooghe, L. and Marks, G. (Year: 2016) Community, scale, and regional governance: A postfunctionalist theory of governance (vol II), Oxford: Oxford University Press.

Hooghe, L., Marks, G., Schakel, A.H., Niedzwieecki, S., Chapman Osterkatz, S. and ShairRosenfield, S. (Year: 2016) Measuring regional authority: A postfunctionalist theory of governance (vol 1), Oxford: Oxford University Press.

Hovik, S. and Hanssen, G.S. (Year: 2015) The impact of network management and complexity on multi-level coordination, Public Administration, 93(2): 506-23. doi: 10.1111/padm.12135

Jessop, B. (Year: 2016) Territory, politics, governance and multispatial metagovernance, Territory, Politics, Governance, 4(1): 8-32. doi: 10.1080/21622671.2015.1123173

Kay, A. (Year: 2003) Evaluating devolution in Wales, Political Studies, 51: 51-66. doi: $10.1111 / 1467-9248.00412$

Klijn, E.-H. and Koppenjan, J. (Year: 2012) Governance network theory: past, present and future, Policy \& Politics, 40(4): 587-606. 
Mackie, P. (Year: 2015) Homelessness prevention and the Welsh legal duty: lessons for inter-national policies, Housing Studies, 30(1): 40-59. doi: 10.1080/02673037.2014.927055 Mackie, P., Thomas, I. and Bibbings, J. (Year: 2017) Homelessness prevention: reflecting on a year of pioneering Welsh legislation in practice, European Journal of Homelessness, 11(1): 81-107.

Marsh, D. (Year: 2011) The new orthodoxy: the differentiated polity model, Public Administration, 89(1): 32-48. doi: 10.1111/j.1467-9299.2010.01897.x

Martin, S. and Guarneros-Meza, V. (Year: 2013) Governing local partnerships: does external steering help local agencies address wicked problems?, Policy \& Politics, 41(4): 585-603.

Morgan, R. (Year: 2002) Speech to the national centre for public policy (11 December, Swansea)www.sochealth.co.uk/the-socialist-health-association/sha-country-and-branchorganisation/sha-wales/clear-red-water/

Peters, B.G. (Year: 2010) Metagovernance and public management, In D.Osborne (ed) The new public governance?, Oxford: Routledge, pp 36-51.

Peters, B.G. (Year: 2013) Toward policy coordination: alternatives to hierarchy, Policy \& Politics, 41(4): 569-84.

Rabey, T. (Year: 2015) Governance, coherence and capacity: Policy making in smaller countries, Cardiff: Public Policy Institute for Wales, https://sites.cardiff.ac.uk/ppiw/files/2015/10/Connection-coherence-and-capacity_Policymaking-in-small-countries-final-report-FINAL.pdf

Rhodes, R.A.W. (Year: 1997) Understanding governance, Buckingham: Open University Press.

Rhodes, R.A.W. (Year: 2007) Understanding governance: ten years on, Organization Studies, 28(8): 1243-64. doi: 10.1177/0170840607076586

Rutter, J., Marshall, E. and Sims, S. (Year: 2012) The 'S' actors: Lessons from IFG's policy success reunions, London: Institute for Government.

Sharpe, L.J. (ed.) (Year: 1993) The rise of meso government in Europe, London: Sage. Sørensen, E. and Torfing, J. (Year: 2009) Making governance networks effective and democratic through metagovernance, Public Administration, 87(2): 234-58.

Stevens, V. and Verhoest, K. (Year: 2016) How to metagovern collaborative networks for the promotion of policy innovations in a dualistic federal system?, The Innovation Journal: The Public Sector Innovation Journal, 21(2): article 2.

Torfing, J. (Year: 2016) Metagovernance, In C.Ansell and J.Torfing (eds) Handbook on theories of governance, Cheltenham: Edward Elgar, pp 525-37. 
Wanna, J. (Year: 2014) Regional political leadership, In R.A.W.Rhodes and P.'t Hart (eds), The oxford handbook of political leadership, Oxford: Oxford University Press, pp 564-79.

Welsh Assembly Government (Year: 2009) Ten year homelessness plan for wales 20092019, Merthyr Tydfil: Welsh Assembly Government.

Welsh Government (Year: 2018) Draft budget 2019-20: Outline proposals, https://beta.gov.wales/sites/default/files/publications/2018-10/2019-2020-outline-draftbudget-narrative_0.pdf 